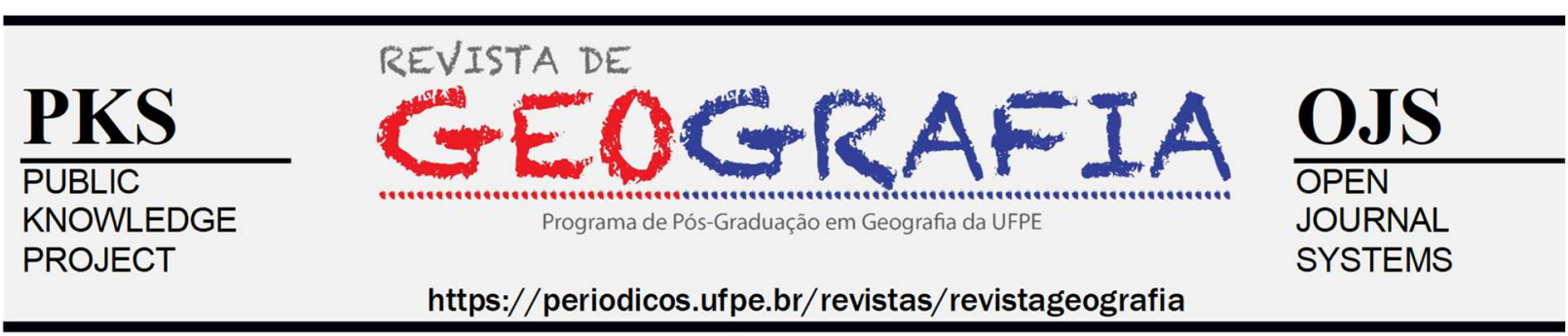

\title{
RESTRIÇÕES AMBIENTAIS AO ADENSAMENTO POPULACIONAL E DAS EDIFICAÇÕES NA ÁREA URBANA DO MUNICÍPIO DE PARANAGUÁ, PARANÁ, BRASIL
}

\author{
Emerson Luis Tonetti ${ }^{1}$, João Carlos Nucci² ${ }^{2}$ Emerson Luís Pawoski da Silva ${ }^{3}$, Leandro Ângelo \\ Pereira $^{4}$
}

\begin{abstract}
${ }^{1}$ Biólogo, doutor em Geografia, professor, Instituto Federal do Paraná campus Paranaguá, eixo tecnológico de meio ambiente, programa de pós-graduação em Ciência Tecnologia e Sociedade; Filiação: Instituto Federal do Paraná-campus Paranaguá. E-mail: emerson.tonetti@ifpr.edu.br; ORCID: http://orcid.org/0000-0003-3325-0615

${ }^{2}$ Biólogo e doutor em Geografia Física (USP), professor do Departamento de Geografia da Universidade Federal do Paraná; Filiação: Universidade Federal do Paraná; e-mail: nucci@ ufpr.br; ORCID: http://orcid.org/0000-00033325-0615

${ }^{3}$ Biólogo pela (Unespar), Especialista em Gestão Ambiental e Desenvolvimento Sustentável (UNINTER) e Mestre em Ciência, Tecnologia e Sociedade (IFPR); Filiação: Instituto Federal do Paraná-campus Paranaguá; e-mail: emprovoski@gmail.com; ORCID: http://orcid.org/0000-0003-1355-8698

${ }^{4}$ Biólogo, doutor em Ecologia e Conservação, professor, Instituto Federal do Paraná campus Paranaguá, eixo tecnológico de meio ambiente, programa de pós-graduação em Ciência Tecnologia e Sociedade; Filiação: Instituto Federal do Paraná-campus Paranaguá; e-mail: leandro.pereira@ifpr.edu.br; ORCID: https://orcid.org/0000-00016055-8063
\end{abstract}

Artigo recebido em 04/05/2020 e aceito em 28/02/2021

\begin{abstract}
RESUMO
O adensamento populacional e das edificações geralmente ocorre sem a devida consideração das restrições ambientais, comprometendo os processos ecológicos, a qualidade do ambiente e o bem estar humano. Nesse sentido, o objetivo da pesquisa foi identificar os elementos que atuam restringindo o adensamento com o intuito de fornecer subsídios para salvaguardar parte dos processos ecológicos que possam auxiliar na melhoria da qualidade ambiental e de vida em Unidades de Paisagem delimitadas na área urbana do município de Paranaguá, no litoral do estado do Paraná. O estudo foi baseado na linha da Ecologia Urbana, destacando os elementos estruturantes da paisagem para a elaboração da carta temática de restrições ao adensamento, tendo como base a dinâmica inferida da paisagem de acordo com quinze elementos de restrições ao adensamento. Todas as oito Unidades de Paisagem identificadas apresentaram restrições para o adensamento populacional e das edificações. Apenas as unidades com predominância do uso residencial e vias que concentram o uso comercial e serviços possuem as restrições cobertura vegetal reduzida ou ausente, arborização viária reduzida ou ausente, pontos de inundações frequentes e baixa potencialidade para o deslocamento não motorizado que poderiam ser removidas ou alteradas. Através desse trabalho de planejamento e monitoramento dos processos ecológicos para melhorar os indicadores de qualidade do ambiente e, na ausência de outras restrições, as unidades poderiam receber adensamento, respeitando os limites da paisagem.
\end{abstract}

Palavras-chave: Unidade de Paisagem; Qualidade do ambiente urbano; Ecologia Urbana.

Tonetti e at al., 2021

ISSN 0104-5490 313

This work is licensed under a Creative Commons Attribution-NonCommercial-NoDerivatives 4.0 International License 


\title{
ENVIRONMENTAL RESTRICTIONS TO THE INCREASE OF POPULATION AND BUILDING DENSITIES IN THE URBAN AREA OF THE CITY OF PARANAGUA, PARANA, BRAZIL
}

\begin{abstract}
Population and building densification usually occurs because of the lack of environmental restrictions which compromise ecological processes, the quality of environmental and human well-being. The aim of this research was to identify the restricting elements of densification to provide subsidies to safeguard part of the ecological processes that can help to improve the environmental and life quality on Landscape Units delimited in the urban area of the city of Paranagua, on the coast of the State of Parana. The study was based on Urban Ecology and emphasizes the structural elements of landscape to elaborate the thematic map of density restrictions. This map was based on fifteen elements of restriction of densification inferred by the dynamics of the landscape. Each one of the eight identified Landscape Units presented restrictions in population and building densities. Only the predominantly residential units with streets that concentrate commercial and service uses have the restrictions restricted or absent vegetation, reduced or absent road afforestation, existing flood points and low potential for non-motorized displacement that could be removed or altered. Through this planning and ecological process monitoring to improve the quality indicators of the environment and in the absence of other restrictions, and respecting the limits of the landscape, the densification could occur.
\end{abstract}

Keywords: Landscape Unit; Urban environment quality; Urban Ecology.

\section{INTRODUÇÃO}

Cidades podem crescer rapidamente, alterando os usos da terra e os processos ecológicos que sustentam a qualidade do ambiente urbano. O entendimento dessas mudanças é fundamental para direcionar o planejamento urbano, evitando que capacidades do ambiente sejam rompidas, provocando mudanças indesejáveis dessa qualidade (ROSIN; BENINI, 2018).

Em muitas cidades o adensamento populacional e das edificações é promovido considerando apenas a presença de alguns aspectos da infraestrutura urbana, desconsiderando outros que podem atuar como restrições a essa compactação (DIAS; SALINAS CHÁVEZ, 2019).

Para salvaguardar a qualidade do ambiente, as propostas de adensamento populacional e de edificações, além da presença de infraestrutura básica, tais como rede de abastecimento de água, de esgoto e de energia elétrica, devem considerar outros elementos que compõem e determinam a potencialidade das paisagens, como, a cobertura vegetal, as vias com tráfego intenso de veículos pesados e os espaços de uso público para o lazer, pois também são elementos importantes para o atendimento às necessidades dos habitantes.

Tonetti e at al., 2021

ISSN 0104-5490

314

This work is licensed under a Creative Commons Attribution-NonCommercial-NoDerivatives 4.0 International License 
O entendimento dos processos urbanos requer modelos capazes de lidar com questões complexas. Nessa perspectiva, diferentes campos da ciência têm realizado estudos urbanos que estão tendendo para um modelo interdisciplinar e transdisciplinar (ADLER; TANNER, 2015).

Um exemplo disso seria o uso do conceito paisagem na sua abordagem sistêmica (MATEO RODRIGUEZ; SILVA; CAVALCANTI, 2004) que, de acordo com Wu (2014), tem agregado, em uma plataforma comum, profissionais e pesquisadores de diferentes áreas.

Mais especificamente, a abordagem sistêmica seria um meio para obter a síntese espaço temporal dos elementos de certa unidade de estudo, inclusive daqueles que transcendem a ela, para se atingir uma adequada projeção para o futuro; as unidades de estudo, delimitadas espacial e temporalmente pelo pesquisador, considerando-se a sua homogeneidade, são denominadas de Unidades de Paisagem (UPs) (MONTEIRO, 2000).

Em outras palavras, as UPs podem ser interpretadas como unidades sistêmicas de análise em determinada escala, em um determinado tempo, para entender a paisagem, com base em seus elementos constituintes (BERTRAND, 1972; MONTEIRO, 2000), considerando para isso, a inferência da função (dinâmica ou processo) com base no estudo dos elementos que se destacam na UP, como resultado das forças que lhe deram origem (BERTRAND, 1972; MONTEIRO, 2000).

$\mathrm{Na}$ aplicação do conceito de UP pode-se analisar a interação entre os elementos da natureza e da sociedade, resultando no conhecimento estrutural e dinâmico que fornece subsídio ao entendimento sobre a potencialidade de cada UP, ou seja, seus limites e suas aptidões para cada uso objeto de localização (MCHARG, 1971; MONTEIRO, 2000; WU, 2014). Desta forma, os elementos seriam responsáveis pelos processos ecológicos que ocorrem na paisagem (WU, 2014), podendo caracterizar problemas na UP indicando, por exemplo, uma restrição ao processo de adensamento urbano, evitando-se assim processos ecológicos indesejáveis e a redução da qualidade ambiental e do bem estar humano (NUCCI, 2008; 2008, WU, 2014).

Nessa linha, o estudo dos componentes ecológicos, sob a perspectiva da Ecologia Urbana, fornece informações mais imediatas e compreensão de síntese e espacializada em produtos cartográficos sobre vegetação, solo, clima, biodiversidade, habitação e ação humana (PICKETT el al., 2016), organizando um diagnóstico que pode subsidiar medidas de redução da deterioração da capacidade funcional do ambiente, ou seja, dos serviços ecossistêmicos que estão associados à qualidade do ambiente urbano e a qualidade de vida (GUERRY et al., 2015). 
Os elementos do ambiente (aspectos físicos, químicos e biológicos), ao serem confrontados com os elementos econômicos e socioculturais, seriam orientadores do planejamento na determinação do uso e cobertura da terra, caracterizando um tipo de planejamento designado de planejamento restritivo (MCHARG, 1971; GOMES-OREA, 1978). Assim, o presente trabalho evidencia os elementos da paisagem urbana que possam atuar como restrições ao adensamento populacional e das edificações em Unidades de Paisagem, com o propósito de alertar que se o adensamento ocorrer, problemas podem se agravar e processos ecológicos podem sofrer mudanças acarretando em redução da qualidade ambiental e do bem estar humano.

O Plano Diretor de Desenvolvimento Integrado de Paranaguá (PARANAGUÁ, 2007), propõe o adensamento populacional pela verticalização das edificações, devido o município estar inserido na maior área contínua de Floresta Atlântica do Brasil, em boas condições de conservação e, portanto, enfrentar restrições jurídico-ambientais para a expansão horizontal urbana.

Sendo assim, o objetivo do estudo de caso foi o de identificar nas Unidades de Paisagem os elementos que atuam restringindo o adensamento com o intuito de fornecer subsídios para salvaguardar parte dos processos ecológicos que possam auxiliar na melhoria da qualidade ambiental e de vida.

\section{METODOLOGIA}

\section{Área de estudo}

Na estreita planície quaternária, da região costeira do Estado do Paraná, encontram-se os municípios de Antonina, Guaraqueçaba, Guaratuba, Matinhos, Morretes, Pontal do Paraná e Paranaguá e esses inseridos no maior remanescente contínuo e em bom estado de conservação de Floresta Atlântica brasileira. Em decorrências das interações e conflitos socioambientais, como desmatamento e urbanização, as dinâmicas sociais, econômicas e ecológicas são foco de diversos estudos, especialmente, as ecológicas (CUNICO, 2016). O município de Paranaguá destaca-se dos demais pela presença de um dos maiores portos do Brasil, o porto Dom Pedro II, que atua como um indutor da economia local, tornando o município o polo econômico 
regional. Na área urbana de Paranaguá concentra-se, praticamente, a metade da população dos sete municípios do litoral do estado, 153.666 habitantes, com taxa de urbanização de 96,38\%, com densidade demográfica média de 188,32 habitantes $/ \mathrm{km}^{2}$ (IPARDES, 2020). A área de estudo, delimitada na Figura 1, apresenta $11,64 \mathrm{~km}^{2}$, o que corresponde a 12,25\% da área urbana total de Paranaguá.

FIGURA 1 - LOCALIZAÇÃO DA ÁREA DE ESTUDO COM ALGUNS PONTOS DE REFERÊNCIA.

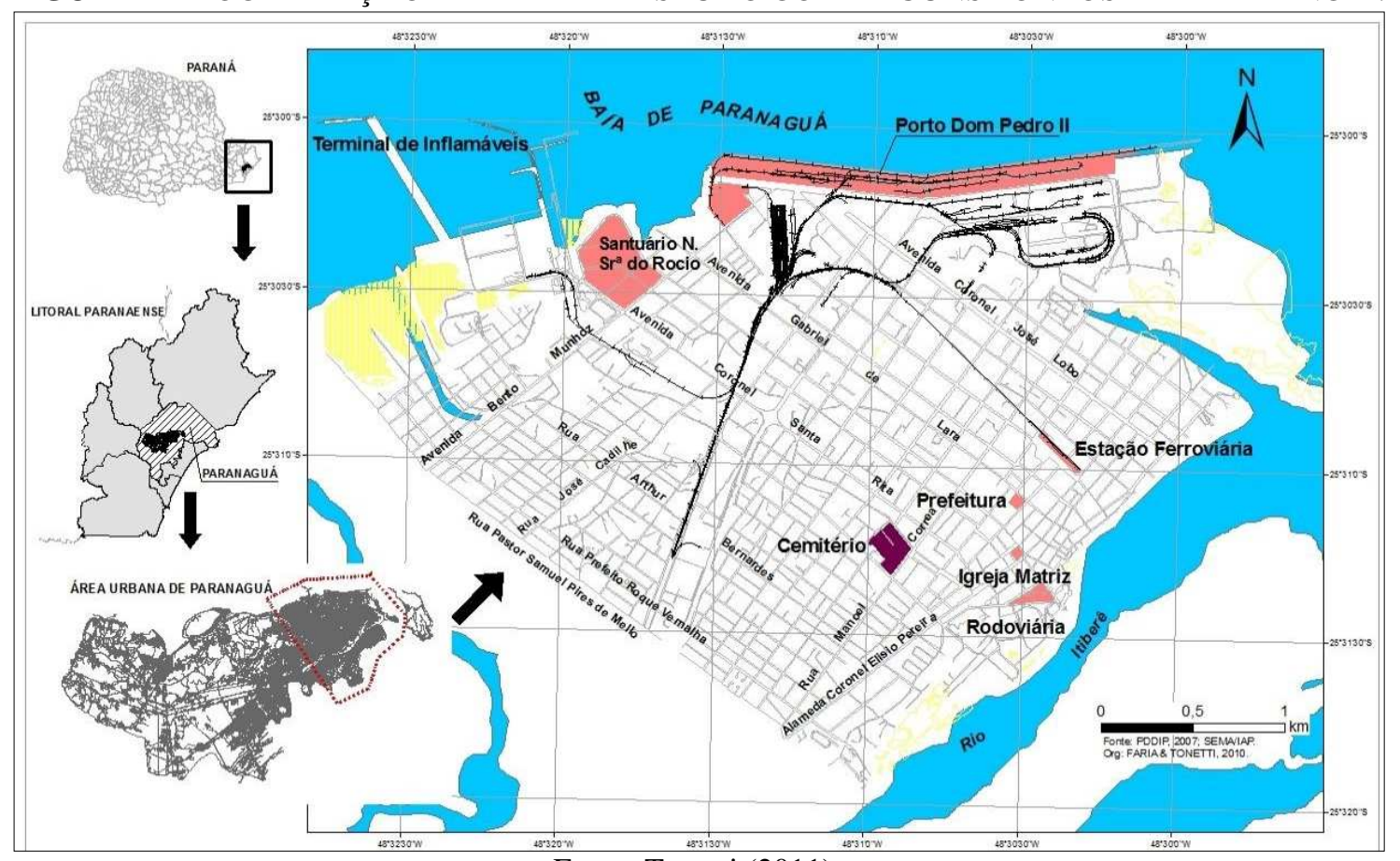

Fonte: Tonetti (2011).

O plano diretor de desenvolvimento integrado do município (PARANAGUÁ, 2007) prevê, ao longo das principais vias de acesso, o adensamento populacional e das edificações por verticalização, considerando, apenas, a presença da infraestrutura urbana instalada.

\section{Procedimentos}

Para identificar e destacar os elementos da paisagem que atuam restringindo o adensamento, o presente trabalho consistiu na elaboração da carta de restrições ao adensamento nas oito Unidades de Paisagem (UP) delimitadas por Tonetti e Nucci (2019), com base nos critérios apresentados nas cartas temáticas e nos quadros de correlações de critérios, dos quais, 
depreenderam-se suas potencialidades (limites e aptidões), pela inferência da dinâmica vinculada a cada critério.

Os limites ou problemas em cada UP, destacados por Tonetti e Nucci (2019), tendo a visão do planejamento restritivo (MCHARG, 1971; GOMES-OREA, 1978), foram considerados, nesta pesquisa, como elementos de restrições ao adensamento em cada uma das Unidades de Paisagem do local de estudo. Assim, foram selecionados para compor a carta de restrições ao adensamento nas UPs urbanas, do município de Paranaguá.

$\mathrm{Na}$ composição da carta de restrições ao adensamento, quinze limites dos elementos da paisagem foram utilizados: (1) cobertura vegetal reduzida ou ausente, (2) arborização viária reduzida ou ausente, (3) presença intensa e dispersa de usos comerciais e serviços, (4) predomínio de usos com maior potencial de causar poluição, (5) baixa oferta de espaços de uso público e livres de edificações, (6) áreas desprovidas de esgotamento sanitário, (7) residências próximas a usos com risco de explosão, (8) presença de Áreas de Preservação Permanente, (9) presença de tráfego intenso de trens de carga, (10) vias com tráfego intenso de veículos leves com congestionamentos frequentes, (11) vias com tráfego intenso de veículos pesados, (12) baixa potencialidade para o deslocamento do pedestre, (13) baixa potencialidade para o deslocamento do ciclista, (14) alagamentos frequentes e (15) presença de imóveis tombados pelo patrimônio histórico.

As Áreas de Preservação Permanente foram determinadas conforme o Código Florestal Brasileiro (BRASIL, 2012).

Para fins de análise e discussão da carta temática, foram adotadas a classificação e a descrição das UPs elaboradas por Tonetti e Nucci (2019) na área de estudo, sendo estas:

- UP-I ou Unidade de Paisagem denominada Usos e Vias Potencialmente Causadores de Poluição com “Ihas” Residenciais. Essa UP engloba toda área portuária, grande parte das empresas direta ou indiretamente relacionadas ao Porto Dom Pedro II e suas respectivas vias de acesso, que apresentam alto potencial para gerar poluição, como os armazéns e as empresas encarregadas da manutenção de equipamentos portuários. Os poucos núcleos residenciais geralmente encontram-se envoltos por usos com alto potencial de causar poluição e muitas vezes com potencial risco de explosão;

- UP-II ou Unidade de Paisagem chamada de Interesse Patrimonial e Turístico. As áreas com interesse patrimonial e que foram delimitadas por leis municipais ou federais e/ou 
com forte interesse turístico. Esta categoria, foi subdividida em UP - IIa, que corresponde ao Centro Histórico do Município de Paranaguá e a sua faixa de proteção e em UP-IIb, relacionada ao Santuário de Nossa Senhora do Rocio e seu entorno;

- UP-III ou Unidades de Paisagem denominadas de APPs (Áreas de Preservação Permanente) com uso residencial. Nesta categoria, foram delimitadas três UPs, que expandiram-se sobre a projeção da ocorrência original dos manguezais da Baía de Paranaguá e/ou da faixa marginal de proteção do Rio Itiberê, com predomínio do uso residencial com infraestrutura urbana consolidada e os remanescentes da cobertura vegetal estão sob forte pressão do uso residencial ou portuário;

- UP-IV ou UP denominada de Residencial com Vias Comerciais. Apresentam visualmente, predomínio do uso residencial e com a concentração de atividades comerciais em algumas vias, com infraestrutura urbana consolidada. Nesta categoria, foram delimitadas duas UPs. Sendo a primeira, encontrada na Zona de Requalificação Urbana (ZRU) e a segunda na Zona de Interesse Portuário (ZIP) segundo o Plano Diretor de Desenvolvimento Integrado de Paranaguá (PARANAGUÁ, 2007).

Após a composição da referida carta, cada restrição foi analisada e discutida no conjunto da área de estudo e procedeu-se a análise e a discussão do conjunto das restrições em cada uma das UPs.

\section{RESULTADOS}

No local de estudo estão delimitadas quatro Unidades de Paisagem principais e suas respectivas subdivisões, constituindo oito UPs. A UP I se destaca das demais pelo tamanho, pelos elementos da paisagem diferenciados em relação as demais UPs. A UP-IIa é uma das unidades mais densamente edificada e habitada, enquanto que a UP IIb, apresenta características opostas. As UPs IIIa, IIIb e IIIc estão assentadas no que originalmente eram áreas de manguezais, constituindo áreas urbanizadas que tiveram expansão muito rápida e desordenada resultando em locais com infraestrutura urbana precária. As UPs IVa e IVb, são decorrentes de processo de planejamento urbano e se destacam das demais pela presença de vias que concentram atividades comerciais e serviços. 
Revista de Geografia (Recife) V. 38, No. 1, 2021

Em relação à localização, as Unidades estão distribuídos na área de estudo da seguinte forma: UP-I da costa para o interior e sendo a maior Unidade; UP-II e UP-III nas proximidades costeiras; e UP-IV no interior. Os resultados encontrados demonstram a existência de elementos da paisagem que atuam restringindo o adensamento populacional e das edificações em todas essas UPs.

A Figura 2 apresenta as Unidades de Paisagem da área de estudo e as restrições para o adensamento populacional e das edificações identificadas nesta pesquisa.

FIGURA 2 - CARTA DE RESTRIÇÃO AO ADENSAMENTO NAS UNIDADES DE PAISAGEM NO MUNICÍPIO DE PARANAGUÁ, PARANÁ. A ÁREA EXISTENTE ENTRE AS UNIDADES DE PAISAGEM, REPRESENTA A FAIXA DE TRANSIÇÃO ENTRE ELAS.

\begin{tabular}{|l|l|l|l|}
\hline & \\
\hline & & \\
\end{tabular}

Tonetti e at al., 2021

ISSN 0104-5490 
Revista de Geografia (Recife) V. 38, No. 1, 2021

\begin{tabular}{|c|c|c|c|}
\hline N & $\begin{array}{c}\text { Unidade de Paisagem IVa e IVb (UP IVa } \\
\text { e IVb) }\end{array}$ & & $\begin{array}{c}\text { 11- Vias com tráfego intenso de veículos } \\
\text { pesados }\end{array}$ \\
\hline$\searrow$ & $\begin{array}{c}\text { 1- Cobertura vegetal reduzida ou ausente } \\
\text { 2- Arborização viária reduzida ou ausente }\end{array}$ & & $\begin{array}{c}\text { 12- Baixa potencialidade para o } \\
\text { deslocamento do pedestre }\end{array}$ \\
\hline & $\begin{array}{c}\text { 13- Baixa potencialidade para o } \\
\text { deslocamento do ciclista }\end{array}$ \\
\hline & $\begin{array}{c}\text { 4- Intensidade de usos com maior } \\
\text { potencial para causar poluição }\end{array}$ & & $\begin{array}{c}\text { 15- Presença de imóveis tombados pelo } \\
\text { patrimônio histórico }\end{array}$ \\
\hline
\end{tabular}

Fonte: Prefeitura de Paranaguá e trabalho de campo.

Organização: os autores.

Sobre as limitações ao adensamento, constatou-se que das quinze restrições, a UP I apresentou doze, a UP IIb quatro e as demais, apresentaram entre cinco e sete restrições.

A cobertura vegetal reduzida ou ausente é uma restrição que se apresenta nas UPs I, IIa, IIIc, IVa e IVb.

Excetuando-se a UP IIa, a oferta de espaços de uso público para o lazer é reduzida, havendo uma concentração desses espaços na referida UP.

A presença de pontos de alagamentos obstruindo vias de deslocamento de veículos atuam como restrições nas UPs I, IIa, IIIc, IVa e IVb.

Quatro das oito UPs, I, IIIa, IIIc e IVb, apresentam restrições ao adensamento por causa da presença de áreas desprovidas de esgotamento sanitário. A restrição denominada de baixa potencialidade para o deslocamento do pedestre e do ciclista é uma realidade em quase todas as categorias, com exceção nas UPs II, onde as calçadas permitem melhor deslocamento e continuidade ao pedestre.

As Unidades de Paisagem denominadas de APPs com Uso Residencial, UP-III, assim como partes das outras UPs, por ocuparem a faixa de proteção dos corpos d água já se configura restrição ecológica ou impedimento legal ao adensamento. Além disso, estas unidades apresentam problemas relacionados com a ausência da infraestrutura para o esgotamento sanitário, arborização viária reduzida ou ausente e baixa potencialidade para o deslocamento não motorizado.

A Unidade de Paisagem denominada de Usos e Vias Potencialmente Causadores de Poluição com "Ilhas" Residenciais, UP I, apresenta doze dos quinze critérios adotados para evidenciar as restrições ambientais ao adensamento populacional e das edificações. As poucas residências desta unidade encontram-se isoladas em meio a usos e vias com alto potencial para 
causar poluição. Acrescenta-se a isto a proximidade destas residências a atividades com risco de explosão e aos sérios problemas de infraestrutura para o esgotamento sanitário. As dinâmicas do porto, e das indústrias relacionadas e ele, exigem vias com intensidade de tráfego de veículos pesados, ferrovia, usos com alto potencial de causar poluição e predomínio de residências próximas a usos com risco de explosão, todas consideradas como restrições ao adensamento na UP I.

A Unidade de Paisagem Interesse Patrimonial e Turístico, UP-IIa, onde se localiza o centro comercial e administrativo do município, apresenta cobertura vegetal reduzida, ausência de ciclovias, grande número de vias com tráfego intenso de veículos leves que está associado a intensidade dos usos comerciais e a presença de pontos de alagamentos frequentes que dificultam o deslocamento nesta área durante as precipitações. A pequena UP IIb que corresponde ao Santuário de Nossa Senhora do Rocio e ao seu entorno, encontra-se tombada pelo patrimônio histórico, caracterizando restrição ao adensamento. Além disso, esta unidade encontra-se isolada e sob forte pressão da expansão das atividades relacionadas ao porto Dom Pedro II. Muitas destas atividades estão relacionadas com a manipulação de materiais explosivos e por isso toda a área encontra-se sob este risco, o que configura, uma forte restrição ao adensamento. Também, a UP apresenta baixa potencialidade dos benefícios da arborização viária e do deslocamento com bicicleta.

As áreas com predomínio de uso residencial e com algumas vias onde há muitas atividades comerciais e denominadas de Unidades de Paisagem Residencial com Vias Comerciais (UPs IVa e IVb), compartilham uma série de restrições ao adensamento, como: cobertura vegetal reduzida ou ausente, arborização viária reduzida ou ausente, pontos de inundações frequentes e baixa potencialidade para o deslocamento não motorizado. Estas duas unidades diferem, respectivamente, em relação aos problemas relacionados com as vias de tráfego intenso de veículos leves e disponibilidade de esgotamento sanitário.

\section{DISCUSSÃO}

Os critérios representados pelos ícones em cada uma das UPs na Figura 2 destacam visualmente o tipo e a quantidade de restrições ao adensamento populacional e das edificações no local de estudo. Isto, permite o planejamento de estratégias de intervenção e prevenção dos 
processos ecológicos e dos serviços ecossistêmicos em cada unidade, em relação as prioridades que se apresentam na unidade e no conjunto delas. Constituindo desta forma, o chamado planejamento restritivo teorizado por MCHarg (1971) e Gomes-Orea (1978), na linha da Ecologia Urbana (WU, 2014; PICKETT et al. 2016).

Visto que essas restrições emanaram da análise dos elementos estruturantes de cada unidade e da inferência da dinâmica sobre eles (TONETTI; NUCCI, 2019), as mesmas refletem os problemas presentes em relação à qualidade dos processos ecológicos que estão ocorrendo em cada UP. Dessa forma, isso permite otimizar o planejamento e o uso dos recursos disponíveis para as intervenções, com base na especificidade de cada problema/limite, direcionando o que deve e/ou pode ser feito, em termos de possibilidades de atividades urbanas, em cada um desses locais. Cada nova atividade interfere na dinâmica da UP, reforçando e/ou gerando ações na complexa teia de relações do sistema urbano considerado (WU, 2014; ADLER; TANNER, 2015; KABISCH; QURESHI; HAASE, 2015).

A presença de usos comerciais e serviços concentrados em determinada região da cidade, como critério do uso e ocupação da terra, para a avaliação da qualidade ambiental urbana (NUCCI, 2008) proporcionou resultado semelhante ao encontrado por Minaki (2009), que avaliou, a cidade de Guararapes no Estado de São Paulo.

Três das quatro classes de UPs (I, II e III) possuem restrições que dificilmente serão alteradas para permitir o adensamento populacional e das edificações, sendo essas as presenças de usos portuários e correlatos, Áreas de Preservação Permanente e áreas e imóveis tombados pelo patrimônio histórico. A cobertura vegetal reduzida ou ausente é uma restrição que se apresenta nas áreas mais densamente ocupadas pela população ou por edificações, que são as UPs I, IIa, IIIc, IVa e IVb. Esse critério associado com a redução ou a ausência da arborização viária em todas as UPs demonstra a fragilidade das unidades na manutenção dos processos ecológicos em geral, visto que a vegetação, sistemicamente, atua em todos (NUCCI, 2008), destacando os processos hídricos, reduzindo o escoamento superficial e aumentando a infiltração de água no solo (BUCCHERI-FILHO, 2010; NIEMELÄ, 2014), reduzindo a frequência dos alagamentos (HERZOG, 2013).

A baixa oferta de espaços de uso público para o lazer é reduzida em todas as UPs, exceto na UP IIa, como apontado por Tonetti, Nucci e Valaski (2012), contradizendo a recomendação de Barton e Tsourou (2000) da necessidade de equipamentos públicos para o lazer nas 
proximidades das residências e que podem estimular o deslocamento não motorizado em viagens curtas e favorecer a redução da emissão de poluentes (ROSIN; BENINI, 2018).

A concentração dos usos portuários e industriais na UP I, foram destacados como indutores do tráfego de caminhões e trens, consequentemente, potenciais fontes da emissão de ruídos e de poluentes na respectiva unidade (TONETTI; NUCCI; VALASKI, 2016). Níveis acima de 90 decibéis, nesta unidade, foram comuns no estudo realizado por Teixeira e Tonetti (2008). Da mesma forma, Gugartz et al. (2018) encontraram níveis elevados de poluentes do ar em cascas de árvores nas proximidades das vias e dos usos portuários e industriais. Estes autores, no momento, investigam o agravamento de problemas respiratórios em residentes da localidade e também, o agravamento destas doenças em residentes de localidades mais afastados da UP I, que estão expostos aos poluentes em função da dispersão pelos ventos e a predominância deles em determinados períodos do ano. Na UP I os núcleos residenciais são encontrados próximos a usos com potencial risco de explosão e incêndio, como apresentado por Gouvêa e Tonetti (2018), que destaca a incompatibilidade de usos (TONETTI; SCHRÖDER; NUCCI, 2015, TONETTI; NUCCI; VALASKI, 2016) na UP, bem como as incongruências do zoneamento urbano presentes no local de estudo (FREITAS; TONETTI, 2016).

As vias de acesso com intensidade de tráfego de veículos leves, com congestionamentos frequentes, estão associadas com a presença de alta concentração de usos comerciais e serviços na UP IIa, onde se localiza o centro comercial e administrativo do município, como destacado por Tonetti, Nucci e Valaski (2016) e indiretamente confirmado por Andrete e Tonetti (2017) pela presença de poluição visual nesta UP, resultante das desconformidades com a legislação vigente em relação a exposição da publicidade ao ar livre.

No total de 16 pontos de alagamentos frequentes são encontrados no conjunto das UPs I, IIa, IIIc, IVa e IVb, que obstruem 35 vias de deslocamento (TONETTI et al., 2013). Estes autores relacionaram os alagamentos a impermeabilização do solo e aumento do runoff, ao nível da maré alta e a precipitação. Nucci et al. (2019) inferem que tais limites ocorrem na paisagem em função da cobertura da terra relacionada com a redução da capacidade de infiltração da água no solo entre outras interferências no ciclo hidrológico no meio urbano. Constituindo, alagamentos e/ou inundações frequentes, como limites da paisagem, em várias cidades no Brasil e no mundo. 
Laureano e Tonetti (2017) mostraram que a adoção de princípios ecológicos no planejamento dos equipamentos urbanos pode melhorar a condição do processo hídrico presente neste tipo de ambiente, o que corrobora o exposto por Buccheri-Filho (2010), Herzog (2013), Niemelä (2014) e Kabisch, Qureshi e Haase (2015) e, em que espaços de uso público não edificados e com vegetação, oferecem recursos ecossistêmicos a sociedade na Unidade da Paisagem em que ocorrem.

A baixa potencialidade para o deslocamento do pedestre e do ciclista é uma realidade no local de estudo, excetuando as UPs II. Contudo, pode-se generalizar que esses tipos de mobilidade urbana não estão contemplados no planejamento urbano municipal, visto que não representam mudanças significativas na mobilidade para os habitantes. Isto foi destacado por Faria, Tonetti e Nucci (2013) ao revisarem as normativas municipais a esse respeito e contraporem com a carta da potencialidade do deslocamento não motorizado nesse local de estudo, onde predomina a descontinuidade da qualidade do deslocamento para o ciclista e para o pedestre, o que torna o ambiente urbano de Paranaguá menos saudável (BARTON; TSOUROU, 2000).

Considerando o exposto, as UPs IVa e IVb, com predominância do uso residencial e vias que concentram o uso comercial e serviços, possuem restrições que podem ser removidas ou alteradas, mediante um trabalho de planejamento e monitoramento dos processos ecológicos, para melhorar os indicadores de qualidade do ambiente. Sendo assim, e na ausência de outras restrições, essas unidades poderiam receber certo adensamento, respeitando os limites das aptidões da paisagem.

\section{CONSIDERAÇÕES FINAIS}

Considerando o objetivo da pesquisa na linha da Ecologia Urbana, todas as Unidades de Paisagem apresentam restrições ao aumento da densidade populacional e das edificações. Algumas dessas restrições dificilmente serão removidas ou alteradas, enquanto outras não, mediante análise e planejamento da paisagem, para salvaguardar os processos ecológicos, a qualidade do ambiente e de vida.

O uso da Unidade da Paisagem como unidade de análise e síntese em imagens em áreas urbanas, permite verificar a semelhança entre as dinâmicas que essas unidades apresentam, pela 
presença de restrições comuns entre elas, para subsidiar planejadores, gestores, profissionais e a população, com informações em um ambiente que sofre mudanças rapidamente.

O acúmulo de pesquisas na área de estudo facilita o entendimento da dinâmica em cada Unidade de Paisagem, permitindo realizar conexões entre os elementos para se aproximar da síntese da paisagem, com o intento da manutenção da qualidade ambiental, processos ecológicos urbanos e bem estar humano, na perspectiva da sustentabilidade urbana.

\section{REFERÊNCIAS}

ADLER, F. R.; TANNER, C. J. Ecossistemas urbanos: princípios ecológicos para o ambiente construído. São Paulo: Oficina de Textos, 2015.

ANDRETE, L. F.; TONETTI, E. L. Poluição Visual no setor histórico do município de Paranaguá - PR. Fórum Ambiental da Alta Paulista, v. 13, p. 35-49, 2017.

BARTON, H.; TSOUROU, C. Health urban planning: A WHO guide to planning for people. Londres: Spon Press (em nome da Organização Mundial da Saúde - WHO). 2000.

BERTRAND, G. Paisagem e Geografia Física Global - esboço metodológico. Série Cadernos de Ciências da Terra, v. 13, p. 1-27, 1972.

BRASIL. Lei complementar $n^{0}$ 12.651, de 25 de maio de 2012. Diário Oficial da União, Brasília, DF, n. 137, 28 mai. 2012. Seção 1, p. 1.

CUNICO, C. (Org.) Zoneamento Ecológico-Econômico do Estado do Paraná. Curitiba: ITCG, 2016.

DIAS, L. C.; SALINAS CHÁVEZ, E. (Org.) Cartografia biogeográfica e da paisagem. Tupã: ANAP, 2019. p. 203-228.

FARIA, G. G.; TONETTI, E.L; NUCCI, J.C. Qualidade e distribuição das calçadas e ciclovias na área central de Paranaguá (PR) Brasil: uma contribuição à mobilidade na cidade. In: XV Simpósio Brasileiro de Geografia Física Aplicada, 2013, Vitória. Anais... Vitória: UFES, 2013. V. 9. p. 31-39.

FREITAS, K. R.; TONETTI, E. L. Usos portuários ou correlatos na área urbana do município de Paranaguá-PR. Revista Nacional de Gerenciamento de Cidades, v. 4, n. 24, 2016. GOMES-OREA, D. El médio físico y Ia planificacion. Madri. CIFCA, 1978. 
GOUVÊA, P. M.; TONETTI, E. L. Avaliação dos riscos de incêndio e explosão na área portuária de Paranaguá-PR. Geografar, v. 12, n. 2, p. 233 - 250, 2017.

GUERRY, A.D.; POLASKY, S.; LUBCHENCO, J.; CHAPLIN-KRAMER, R.; DAILY, G.C.; GRIFFIN, R.; RUCKELSHAUS, M.; BATEMAN, I.J.; DURAIAPPAH, A.; ELMQVIST, T.; FELDMAN, M.W.; FOLKE, C.; HOEKSTRA, J.; KAREIVA, P.M.; KEELER, B.L.; LI, S.; MCKENZIE, E.; OUYANG, Z.; REYERS, B.; RICKETTS, T.H.; ROCKSTRÖM, J.; TALLIS, H.; VIRA, B. Natural Capital and Ecosystem Services Informing Decisions: From Promise to Practice. Proceedings of the National Academy of Sciences, v.112, n.24, p.7348-7355, 2015. GURGATZ, B. M.; OLIVEIRA, R. C.; ANTONIACONI, G.; SALDIVA, P. H. N.; HUERGO, L. F.; REIS, R. A. Spatial Distribution of Atmospheric Pollutants through biomonitoring in tree bark using X-ray fluorescence. Eclética Química Journal, v. 43, p. 59, 2018.

HERZOG, C. P. Cidades para Todos. Rio de Janeiro: Mauad Ltda, 2013.

IPARDES. Instituto Paranaense de Desenvolvimento Econômico e Social. Caderno Estatístico do Município de Paranaguá-PR. 2020. Disponível em: http://www.ipardes.gov.br/cadernos/Montapdf.php?Municipio=83200\&btOk=ok. Acesso em: 30 mar. 2020.

KABISCH, N.; QURESHI, S.; HAASE, D. Human-environment interactions in urban green spaces: A systematic review of contemporary issues and prospects for future research. Environmental Impact Assessment Review, v.50, n.1, p.25-34, 2015.

LAUREANO, F. A.; TONETTI, E. L. Potencialidades dos equipamentos públicos para a implantação de tipologias multifuncionais para redução dos alagamentos frequentes em Paranaguá-PR. Fórum Ambiental da Alta Paulista, v. 13, p. 24-36, 2017.

MATEO RODRIGUEZ, J. M.; SILVA, E.V.; CAVAlCANTI, A. P. B. Geoecologia das Paisagens: uma visão geossistêmica da análise ambiental. Fortaleza: Ed. UFC, 2004.

MCHARG, I. Design with nature. Nova York, Back Edition. 1971.

MINAKI, C. Qualidade ambiental urbana em Guararapes/SP. Dissertação (Mestrado) Departamento de Geografia da Universidade Estadual Paulista - Julho De Mesquita Filho, Presidente Prudente, 2009.

MONTEIRO, C. A. F. Geossistemas: a História de uma Procura. Saint Paul: Contexto, 2000. NIEMELÄ, J. Ecology of urban green spaces: The way forward in answering major research questions. Landscape and Urban Planning, v.125, n.1, p.298-303, 2014. 
NUCCI, J. C. Qualidade Ambiental e Adensamento Urbano: um estudo de ecologia e planejamento da paisagem aplicado ao distrito de Santa Cecília (MSP). 2 ed. Curitiba: Edição do autor, 2008.

NUCCI, J.C.; VALASKI, S.; ESTÊVEZ, L.F.; TONETTI, E.L. Uso da Terra e Qualidade Ambiental Urbana: uma proposta de legenda para mapeamento. GEOgraphia, v.21, n.46, p.7390, 2019.

PARANAGUÁ. Lei Complementar n⿳0 068, de 23 de agosto de 2007. Institui o Plano Diretor de Desenvolvimento Integrado no Município de Paranaguá. Disponível em: https://leismunicipais.com.br/a/pr/p/paranagua/lei-complementar/2007/6/60/lei-

complementar-n-60-2007-institui-o-plano-diretor-de-desenvolvimento-integrado-estabeleceobjetivos-instrumentos-e-diretrizes-para-as-acoes-de-planejamento-no-municipio-deparanagua-e-da-outras-providencias?q=60. Acesso em: 25 abr 2020.

PICKETT, S. T. A.; CADENASSO, M.L; CHILDERS, D.L; MCDONNELL, M.J.; ZHOU, W. Evolution and future of urban ecological science: ecology in, of, and for the city. Ecosystem Health and Sustainability, v.2, n.7, e01229, 2016.

ROSIN, J.A.R.G.; BENINI, S.M. (org). Cidade sustentável: um conceito em construção. Tupã: Associação Amigos da Natureza da Alta Paulista, 2018.

TONETTI, E. L. Potencialidades de adensamento populacional por verticalização das edificações e qualidade ambiental urbana no município de Paranaguá, Paraná, Brasil. 235f. Tese (Doutorado) - Setor de Ciências da Terra, Universidade Federal do Paraná, Curitiba. 2011.

TONETTI, E. L.; NUCCI, J. C.; SOUZA, F. X. S.; VALASKI, S. Alagamentos frequentes na área urbana de Paranaguá-PR. Geografia, v. 22, p. 43-56, 2013.

TONETTI, E. L.; NUCCI, J. C.; VALASKI, S. Espaços livres na área urbana de Paranaguá. Revista da Sociedade Brasileira de Arborização Urbana, v. 7, p. 37-50, 2012.

TONETTI, E. L.; NUCCI, J. C.; VALASKI, S. Espacialização de áreas potencialmente poluídas: proximidade de usos incompatíveis no município de Paranaguá-PR. Revista Nacional de Gerenciamento de Cidades, v. 04, n. 25, p. 33-50, 2016.

TONETTI, E. L.; SCHRÖDER, P. H.; NUCCI, J.C. Risco de explosão: mistura de usos incompatíveis na área urbana de Paranaguá-PR. In: ROSIN, T. A.; ROSIN, T. A. (Orgs). Riscos e vulnerabilidades ambientais. Tupã: ANAP, 2015. p. 119-137. 
TONETTI, E. L.; NUCCI, J. C. Diagnóstico e prognóstico em unidades de paisagem na zona urbana de Paranaguá-PR. In: DIAS, L. C.; SALINAS CHÁVEZ, E. (Org.) Cartografia biogeográfica e da paisagem. Tupã: ANAP, 2019, p. 203-228.

WU, J. Urban ecology and sustainability: the state of the science and future directions. Landscape and Urban Planning, v.125, n.1, p. 209 - 221, 2014. 